\title{
Optics programs at University of Massachusetts/Lowell: the role of a state university in a high-tech state
}

Zoltan Fried, Sergey Broude

Zoltan Fried, Sergey V. Broude, "Optics programs at University of Massachusetts/Lowell: the role of a state university in a high-tech state," Proc. SPIE 1603, Education in Optics, (1 March 1992); doi: 10.1117/12.57838 
Optics programs at UMass/Lowell:

The role of a state university in a high-tech state

\author{
Z. Fried, S. V. Broude
}

Physics Dept., UMass/Lowel1, Lowell, MA, 01854, USA
tel.508/934-3784, fax.508/459-6561
E-mail: Internet <sbroude@rcnvms. rcn. mass. edu>

ABSTRACT

Optics education of both the undergraduate and graduate levels available at the Department of Physics and Applied Physics at the University of Massachusetts-Lowell is discussed. A brief history and motivation for establishing the program is presented. Also included are the undergraduate Optics Option curriculum, course requirements for the M.S. and Ph.D. degrees and a selection of both M.S. and Ph.D. dissertation titles.

\title{
INTRODUCTION
}

By the mid-1970s, it became clear to the Faculty of the Physics Department of the University of Lowell that the standard undergraduate physics curriculum did not appeal to our students. Historically, the undergraduate physics curriculum was designed to expose the students to the whole sweep of physics from Newton to Schrodinger at an introductory and intermediate level. By the senior year some students would choose to further their physics education at the graduate level, others would join the work force in industrial or government laboratories as science/engineer trainees. This pattern of post-baccalaureate career opportunity was the norm during the post World War II era, until the end of 1960s. After that, employment opportunities for college graduates with a B.S. degree in Physics have vanished at a steady rate. This state of affairs was brought on by a confluence of changing circumstances. To mention a few, the off-the-shelf availability of many scientific instruments, steady advances in digital computation and last but not least the cultural changes besetting American society, with "instant gratification" becoming the order of the day. Thus, managers of science or engineering projects lost interest in training new recruits; they were looking for candidates who could be put to work on the first day of employment. Under these circumstances, the only choice available to a physics major who wanted to stay in the field was to apply to graduate school. At the University of Lowell most of the entering freshmen are first generation college students, who plan to join the labor force after completion of an undergraduate education. At that stage, any suggestion of extending their education another four or five years at the graduate level becomes totally unacceptable to most of our entering freshmen. The entering freshman at the University of Lowell wanted to know: "What can you do with a B.S. in Physics?". And to this question we had to respond.

In searching for a branch of physics that could be taught effectively at the undergraduate level and would also provide the student with marketable skills at the completion of a B.S. program, Optics was a natural choice. It 
was quite obvious in the mid-1970s that employment opportunities will have to increase. Another impetus for the choice of Optics stemmed from the fortunate circumstance that several Faculty members of the Physics Department had some expertise in this area.

A Departmental Committee was formed. The Committee members were, in addition to one of the authors (Z.F.), Drs. A. Karakashian, H. Samelson, R. Stimets, Y. Teng, J. Waldman, M. Wilner and C. Wong. In consultation with experts from outside the University, Drs. A. Alfano, R. Forkey, M. Hersher and J. Kuppenheimer, an "Optics Option" program was drafted.

\section{THE UNDERGRADUATE CURRICULUM}

As mentioned in the Introduction, the under-graduate Optics Program was intended to complement, not to supplant, the requirements for the B.S. degree in Physics. This and other considerations, such as staffing and availability of major equipment led us initially to concentrate on four one-semester courses. All course offerings had either a lecture plus laboratory setting, or a combination lecture/laboratory format.

Students enrolled in the Program would start in the Fall semester of their Junior year with a course in Geometrical Optics, a three hour lecture course with a one-per-week laboratory. The student would spend a minimum of three hours in the laboratory. The next course offered in the Spring semester is Physical Optics. The instructional format of this course is again three hours per week of lectures and laboratory hands-on exercises for a minimum of three hours per week. In their Senior year, the students would enroll in the Fall semester in a lecture plus laboratory course with the title "Sources and detectors" which covers a multiplicity of topics (see App. A). The last course of the original sequence of courses offered in the "Optics Option" was a four hour per week lecture/laboratory course dealing with image processing and pattern recognition.

Implementation of the program proceeded at an accelerated pace and by the Fall semester of 1978 an enthusiastic group of students enrolled in the program. The first class was graduated in June of 1980 . It was a relatively smajl class, eight students. Half of them went to graduate school and the other four found employment locally.

In the beginning the program was open to physics majors only. Later on, in response to demand, electrical engineering majors would be accommodated.

Subsequently, two additional courses were added to the curriculum: a lecture/laboratory course on fiber optics and a course on lasers.

The program has been quite successful. Between sixty to eighty students have obtained, in addition to their physics or electrical engineering degrees, a well thought out education in some of the basics of both classical and modern optics. Our graduates had no difficulty in obtaining employment or getting into well known optics graduate schools. 
The list of course required of a physics major with a concentration in Optics Option is:

Fall

College Writing I 3

Calculus I 4

Honors Physics I 3

Intro. Exper. Physics I 2

Elective

Fall

$\begin{array}{lr}\text { Calculus II I } & 4 \\ \text { Honors Physics I I } & 3 \\ \text { Intermed. Exper. Physics I } & 2 \\ \text { Chemistry I } & 3 \\ \text { Chemistry Lab I } & 1 \\ \text { Elective } & 3\end{array}$

Fall

Appl. Math. I

E-Mag I

Advanc. Exper. Physics I 2

Elective

Elective

Fall

Class. Mechanics 3

Senior Seminar 1

Elective 3

Elective 3

Elective 3

Elective

Total credits required $=122$

Total credits "kernel" $=45$

Specialization courses (Electives):

Physical Instrumentation 2

Geom. optics Lab. 1

Electro-Optics 3

Image Processing 4

Optics Project 3

Exper. Laser Optics 2

\section{FRESHMAN YEAR}

Spring

College Writing II 3

Calculus II 4

Honors Physics II 3

Intro. Exper. Physics II 2

Elective

SOPHOMORE YEAR

Spring

Differ. Equat. 3

Intro. Modern Physics 3

Intermed. Exper. Physics II 2

Chemistry II 3

Chemistry Lab II 1

Elective

3

JUNIOR YEAR

Spring

Math. 3

Quant. Mechanics I 4

Physical Optics 3

Advanc. Exper. Physics II 2

Elective 3

\section{SENIOR YEAR}

Spring

Statistics/Thermodynamics 3

Contemp. Physics 3

Elective 3

Elective 3

Elective $\quad 3$ 
At the graduate level, both M.S. and Ph.D. degrees are offered at the Department.

Under M.S. program, there exists an Optical Sciences option which is designed to provide the necessary preparation for students wishing to specialize in such rapidly expanding fields as electro-optics phenomena, lasers and their applications, fiber optics, new optical materials, processes and devices. This option is intended for students who have completed a bachelor's degree program in Physics, Engineering or other sciences. It is offered in cooperation with the Department of Electrical Engineering. The Optical Sciences option emphasizes laboratory research providing the student valuable "hands-on" experience with optical systems and devices. Candidates may elect to do either M.S. Thesis or M.S. Project. An M.S. Thesis involves an original investigation (though not as extensive as that for a Ph.D. Thesis) or construction of a major piece of apparatus. An M.S. Project carries only 3 credits and must be completed in one semester and could be for, example, a review of some topic or construction of a minor piece of apparatus.

At least 30 credit hours are required for the M.S. degree and two course sequences are available:

(a) for students with Physics B.S.:

$\begin{array}{llll}\text { Math. Methods Physics I } & 4 & \text { Laser Physics/Applicat. } & 3 \\ \text { Electro-Optics } & 3 & \text { Electro-Optics Lab. } & 2 \\ \text { Seminars } & 3 & \text { Thesis } & 6-12 \\ \text { Electives } & 3 & \text { or Project } & 3\end{array}$

(b) for students with B.S. in other sciences or engineering:

$\begin{array}{llll}\text { Math. Methods Physics I } & 4 & \text { Laser Physics /Applicat. } & 3 \\ \text { Electro-Optics } & 3 & \text { Electro-Optics Lab. } & 2 \\ \text { Physics of Rad. \&Nucl. I } & 3 & \text { Appl.Quant.Mech. } & 4 \\ \text { Seminars } & 3 & \text { Thesis } & 6-12 \\ \text { Electives } & 3 & \text { or Project } & 3\end{array}$

For the Ph. D. degree, at least 60 credits are required, of which between 15 and 24 must be for Dissertation research. Course requirements include:

$\begin{array}{llll}\text { Math. Methods Phys. I, I I } & 4,4 & \text { Class. Mech. } & 3 \\ \text { Quant. Mech. I, I I } & 4,4 & \text { EM Theory I, I } & 4,4 \\ \text { Advanc. Quant. Mech. } & 3 & \text { Adv. Projects in Phys. } & 3,3 \\ \text { Grad. Seminar } & 1,1 & \text { Phys. Colloquium } & 1,1 \\ \text { Electives } & & \text { Thesis Research } & 15-24\end{array}$


For all of the above graduate sequences, electives are chosen from the following list of courses (Sept'91):

$\begin{array}{llll}\text { Fiber Optics \& Lab. } & 4 & \text { Image Proc. \& Lab } & 4 \\ \text { Solid State Physics } & 3 & \text { Quant um Mech. I (MS) } & 4 \\ \text { Electro-Opt. Syst.Design } & 3 & \text { Optics Inform. Proc. } & 3 \\ \text { Exp. Laser Physics } & 3 & \text { Nonlinear Optics } & 3 \\ \text { Design Sci.Apparata } & 2 & \text { Semicond. Technologies } & 3\end{array}$

It has to be noted here that while lists of required courses stay relatively unchanged over years, the composition of the electives list is periodically modified to reflect the new topics of scientific and engineering interest, and to best utilize specific expertise of instructors, both the University faculty and visiting instructors from industry and other institutions. This approach is a reflection of over-all strategy of the Department to combine solid theoretical training and fundamental research on one hand, with the development of practical skills and applied projects of interest to high-tech industry on the other hand. There is of course a degree of conflict between these two goals. Is the educator's primary obligation to the student in terms of providing an education of lasting value, or to industry in terms of supplying skilled workers?

In order to resolve this "conflict", an Industrial/Faculty Advisory Committee in Optics was created, comprised from representatives of local companies involved with optics and its applications, and the faculty members whose research and instructional experience are related to optics. Selected were the companies with which the Department has or had joint research interests, and/or those which already employ the Department's graduates (B.S.S, M.S.s and Ph.D.s).

The Advisory Committee began its work with the review of existing programs of both undergraduate and graduate degrees, in terms of course sequences and their syllabi. The Committee came up with a series of structural recommendations which are presently being implemented (Creation of a "kernel" curriculum including E\&M, Quantum Theory, Thermodynamics, etc.; Introduction of a special topics lecture series by external lecturers; Development of lab programs with attention to students' creative work and hands-on experience; Theses at $R / D$ locations in the Industry; Team projects in lab courses; Work-study on locations.) Also, industrial members of the Advisory Committee drew up a list of special topics, that their future employees should be exposed to (Optics system analysis; Elements of lens design; Non-imaging optics (incl. light concentrators); Methods of low-level light detection and radiometry (+Lab); Fiber-optics applications (faceplates, image inverters, magnifiers; coupling of fibers to detectors) (+Lab); Optical computing and integrated optics; Computer image processing; Gaussian beam optics; Scanning optical systems; Scattering of light; Fine mechanics for optical instrumentation; Vibration isolation; etc.) Many of the Committee members emphasized an important skill often lacking in graduates even of the best schools: technical writing. This deficiency is being addressed by attention paid by instructors to language in laboratory reports, term papers and theses. 
The fact that UMass/Lowell is only 30 miles north of Boston provides opportunities as well as challenges to our Optics programs. This area, with its Route 128, "America's High Technology Highway", is an extensive job market for our graduates and a substantial pool for recruiting students both at undergraduate and graduate levels. There are a lot of University capabilities for research in physics, and in optics in particular, that the local companies are interested in and are prepared to fund either from their own resources (at least, during better economic periods) or by "farming out" Federal and other large grants. In all of these "markets" however, UMass/Lowell compliments capabilities of other, prominent research institutions located as conveniently in the area: MIT, Harvard, Tufts, etc. Our approach was to foster working relationships with many smaller and medium-sized companies and projects. This is in accordance with the charter of UMass/Lowell as a state-supported regional resource of high quality education and research. As a result of this approach, presently several of our $\mathrm{PhD}$ and MS level research projects are run in cooperation with our graduates working in industry. Some of the projects are worked on partially on the premises of the companies. These companies become sources of summer positions for our students, and many of these students were able to find employment with such companies after graduation.

App. B below lists some of the topics of recent graduate research in optics and related fields at UMass/Lowell.

\section{GENERAL INFORMATION}

UMass/Lowell, founded in 1895, is a large public institution, offering undergraduate and graduate degrees to 14,600 students (1990).

Undergraduate tuition and fees: $\$ 4320$ (state resident), $\$ 9042$ (non-resident). Graduate tuition and fees: $\$ 1760$ (state resident), $\$ 3399$ (non-resident).

Teaching and research assistantships: $\$ 8750$ (Ph.D), $\$ 7250$ (M.S. ).

B.S. degrees in Physics with Optics concentration: 5-10/yr.

M.S. degrees with Optics specialization: 5-6/yr.

$\mathrm{Ph}$. D. degrees with dissertations in optical fields: 2-3/yr.

App. A. Courses of the Undergraduate Optics Program

Geometric Optics

Properties of light. Plane surfaces and prisms. Thin and thick lenses. Mirrors and stops. Matrix methods applied to paraxial optics. Lagrange-Helmholtz invariant. Primary and chromatic aberrations. Ray tracing and Abbe's sine condition. Basic optical instruments, including cameras, telescopes and microscopes.

\section{Physical Optics}

Wave nature of light. Mathematics of wave motion. Electromagnetic theory of light propagation. Reflection and refraction. Fresriel coefficients. Polarization. Interference. Young's experiment. Fringe visibility and 
coherence. Various interferometers. Newton rings and applications. Fraunhofer diffraction by single and multiple apertures and diffraction gratings. Fresnel diffraction.

\section{Electro-optics}

Optical properties of materials: complex dielectric constant; isotropic and anisotropic media polarization. Transmitting materials for visible applications. Optical properties of metals. Sources of electromagnetic radiation: photometry, blackbody radiation, emission spectra of atoms and molecules, incoherent high intensity sources and applications. Introduction to lasers as coherent light sources. Detectors: introduction to photoelectric effect. Semiconductor physics. Photochemistry. Applications of basic principles to various detectors. Applications of the above material to spectrometers and transmitter/receiver systems.

\section{Image processing}

Basic physics of television and other imaging systems. Representation and manipulation of images in digital form. Fourier analysis and filtering of images. Detection of image features such as edges and regions; pattern recognition. 3-dimensional visual perception in man and machine. Examples of image processing tasks from such areas as medicine, industrial inspection and robotics. Laboratory exercises with an image processing system. Ability to program a computer is required.

\section{Lasers}

Introductory treatment of lasers and their applications. Interaction of radiation with matter, including electric and magnetic dipole transitions. The concept of stimulated emission. rate equations. Optical resonators. Collision and line broadening processes. Study of various gas and solid state lasers. Applications to harmonic generation, holography. Optical modulation techniques.

\section{Optics Project}

A project to be completed by either an individual or two students working as a team to design and test an optical system which will involve a synthesis of a substantial number of optics principles and techniques.

\section{Fiber Optics}

Introduction to optical communications. Basic theory of light guiding. Propagation characteristics and focusing effect of an optical waveguide. Optical sources and detectors for fiber communications. Fundamental parameters of optical fibers. Fabrication and testing methods for optical fibers. Laboratory experiments will include optical fiber parameter measurements, sensors, connectors, sources and detectors.

Geometric Optics Lab

Reflection. Refraction. Index of refraction. Thin and thick lenses. Single optical surfaces, mirrors, prisms, films, aberrations, alignment. Telescope, periscope, endoscope. Stops. 
Physical Optics Lab

Michelson and Twyman-Green interferometers. Newton's rings. Optical testing. Multiple beam interference. Diffraction grating. Spectroscopy. Fresnel and Fraunhofer diffraction. reflection of light from a dielectric surface. Polarization. Holography.

Sources and Detectors in Modern Optics Lab

Detectivity of a detector. Absorption and reflection spectroscopy (VIS, IR). Optical coatings. Detector characteristics. Blackbody radiation. Photometry. Crystal optics. Optical properties of thin films. Laser modes. Sources of noise in detector systems.

Imaging systems and Image processing Lab

Image processing facilities. Photographic imaging. Image properties. Image enhancement. Fourier analysis. Optical spatial filtering. Fourier transforms of images and digital spatial filtering. Feature detection and pattern recognition. A short independent project in an area of image processing and pattern recognition.

App.B. Sample list of recent research proposals and dissertations:

(a) Ph. D.

Computer modeling of a fast photo-conducting avalanche switch.

A high-precision reflectometer for sub-millimetre range.

The photo-refractive effect applications to neural networks.

Structural characterization and linear and non-linear optical properties of polymer materials (A.K.M. Rahman, defended 1991).

Studies of laser ablation of solid samples and its plasma formation (Z. W. Huang, 1991).

Optical characterization of thin polymer films: spectral and light scattering experiments and a new theoretical model for ultra-thin films (P. Miller, 1991).

The dielectric properties of conducting polypyrrole in the far infrared (G. Phillips, 1990). 1989).

A prism-coupled surface plasma waves excited MIS Solar cell (W.Berg,

Surface plasma enhanced quantum efficiency of a $\mathrm{Ag}-\mathrm{Ti}-\mathrm{nGaAs}$ junction (M. Rahman, 1988).

Rapid recognition of object skeletons in reduced resolution images (K. Rajasekharan, 1986).

Design of a sub-millimeter ellipsometer (R.Giles, 1986).

Application of single and multiple scattering techniques to optical properties of dielectric media (E. R. Freniere, 1984).

Magneto-optical studies of paramagnetic systems for far-infrared applications (S.S. Madan, 1979)

(b) M.S.

Experiments and modeling in light scattering from particles on dielectric surfaces. 
Measurements of grating efficiency as function of non-conventional angles of incidence and polarization.

The non-linear optical properties of micro-particles suspended in a liquid medium.

Mirror scatter degradation by particulate contamination.

Measurements of optical constants of gamma-irradiated optical materials (C. T. Yang, defended 1991).

Optical switch based on self-focusing, self-defocusing and self-phase modulation of laser beams in a non-linear medium (R.S.Leon, 1991).

Fabrication of sub-micron gratings via holographic microlithography (E. Williams, 1990).

Optical properties of polycrystalline diamond films in far infrared (A. J.Gatesman, 1990).

TIR ring resonator behavior and self-pumped phase conjugation in photo-refractive BaTiO3 (T.H. Yang, 1990). 1989).

Rapid recognition of metallic objects in ambient lighting (E.J.Tobin,

Two-frequency phase ranging in far infrared (S.R. Henion, 1989).

Design and characterization of a high-power alexandrite laser oscillator (S. Schecht, 1984). 